\title{
А. О. АндРОНнИКОВА
}

\section{Онтогенетическая виктимизация личности в ситуации социально-психологической депривации ребенка}

В качестве объекта исследования в данной статье выступил феномен онтогенетической виктимизации личности. Цель данной работы заключается в исследовании влияния социально-психологической депривации на онтогенетическую виктимизацию личности ребенка. В статье рассматривается одна из актуальных и сложнейших задач, вызванная потребностью современного общества в теоретическом анализе феномена виктимности, его проявлении и пути девиктимизации личности находящейся в зоне риска. Определена значимость роли ближайшей социализирующей среды в развитии ребенка, влияние характера его воспитания на специфику психической травматизации. Рассматриваются детерминанты и индукторы онтогенетичекой виктимизации личности и явление социально-психологической депривации. Рассмотрены особенности виктимизации, социально-психологической адаптации и нарушения психологического пространства личности у детей из детского дома. Обозначены закономерности взаимосвязи виктимных синдромов с параметрами нарушенного психологического пространства личности ребенка и социально-психологической адаптацией. Доказано что социально-психологическая депривация может быть определена как детерминанта онтогенетической виктимизации личности ребенка.

Ключевые слова: виктимность, депривация, онтогенез, развитие личности

\section{Ссылка для цитирования:}

Андронникова А. О. Онтогенетическая виктимизация личности в ситуации социальнопсихологической депривации ребенка // Перспективы науки и образования. 2019. № 2 (38). С. 229-239. doi: 10.32744/pse.2019.2.17 


\section{O. O. ANDRONNIKOVA}

\section{Ontogenetic victimization of personality in the situation of socio-psychological deprivation of the child}

The influence of socio-psychological deprivation on ontogenetic victimization of a child's personality is being studied. The paper deals with one of the most urgent and complex problems caused by the need of modern society in the theoretical analysis of the phenomenon of victimization, its manifestation and ways of devictimization of personality at risk. The significance of the role of the nearest socializing environment in the development of the child, as well as the influence of the nature of its education on the specifics of mental trauma, are determined. The determinants and inducers of ontogenetic victimization of personality and the phenomenon of socio-psychological deprivation are reviewed. Features of victimization, socio-psychological adaptation, and violations of the psychological space of personality in children from an orphanage are reviewed. Regularities of the relationship of victimization syndromes with the parameters of the disturbed psychological space of child personality and socio-psychological adaptation are outlined. It is proved that sociopsychological deprivation may be defined as a determinant of the ontogenetic victimization of child personality.

Keywords: victimity, victimization, deprivation, ontogenesis, personality development

\section{For Reference:}

Andronnikova, O. O. (2019). Ontogenetic victimization of personality in the situation of sociopsychological deprivation of the child. Perspektivy nauki i obrazovania - Perspectives of Science and Education, 38 (2), 229-239. doi: 10.32744/pse.2019.2.17 

зависит психологическое благополучие как отдельной личности, так и общества. На сегодняшний день в современном обществе все более отчетливо проявляется ряд определенных изменений. Среди наиболее значимых из них: постоянно ускоряющийся темп жизни; трансформация требований к личностным и поведенческим характеристикам человека, его профессиональным навыкам, умению адекватно реагировать на увеличившееся количество технократических и социальных угроз [5]. Данная проблема получает особую актуальность, когда речь идет о воспитании и развитии личности ребенка.

Социально-психологический аспект проблемы исследования состоит в недостаточной изученности социально психологической депривации, особенностей ее проявления. Среди наиболее актуальных принято выделять: отсутствие работ, где бы исследуемый феномен раскрывался во всей его целостности, представлены исследования отдельных его аспектов (сущностных признаков, технологий и средств коррекции) [20]. В основном современные исследователи сосредотачивают свое внимание на изучении таких видов депривации, как: психическая депривация (Й. Лангмейер и 3. Матейчек), материнская (Бардышевская М.К., Боулби Дж., Шпитц Р.А. и др.). Г.Т. Хоментаускас [23], В.М.Целуйко [24] и Н.А. Целуйко [25], Я.Г. Николаева [15], А.В. Захаров [11], О.В. Соловьева [17] и другие авторы выделяют такие виды депривации как: сенсорная, эмоциональная, двигательная депривация. Работ, посвященных исследованию социально-психологической депривации не много. Между тем потребность в научно подкрепленных знаниях о понятии, особенностях социально-психологической депривации и ее влиянии на виктимизацию личности ощущается в различных сферах деятельности, связанной с воспитанием, психологией, социальной работой.

\section{Основные положения}

В качестве теоретико-методологических оснований исследования выступают концепции развития личности (Л.С.Выготский, А.Н.Леонтьев, Л.И.Божович); положения системно-деятельностного подхода (Б.Г.Ананьев, Б.Ф.Ломов); положения концепции социально-психологической виктимологии личности (А.В. Мудрик, Е.В. Руденский) культурологический подход объясняющий культурологическую обусловленность генезиса личности (А.С. Запесоцкий, Н.С. Злобин, Е.В. Семенюк). Как на одно из центральных положений, определяющих роль социальных условий в психическом развитии ребенка Л. С. Выготский [8], А.В. Запорожец [10], А.Н. Леонтьев [12], Д.Б. Эльконин [26] и др. опирались на положение о пути развития как процессе присвоения социальнокультурного опыта во взаимодействии с социумом. По мнению авторов, в процессе взаимодействия ребенка со взрослыми (родителями и замещающими их лицами) появляются и интериоризируются различные формы психической деятельности ребенка, идет формирование определенных качеств личности.

Учитывая множественность воздействия социальных условий, их многоплановость (в том числе деструктивность) возникает потребность описания сочетанного комплекса структуры факторов, приводящих к виктимности личности. 
Виктимность рассматривается в рамках многих социальных наук. Так в контексте юридической психологии виктимность рассматривается как «повышенная способность человека» в силу его социальной роли и ряда физических и духовных качеств при определенных обстоятельствах «становиться потерпевшим» (Л.В. Франк) [21]. Нами виктимность рассматривается как совокупность свойств человека, обусловленных комплексом социальных, психологических и биофизических условий, способствующих дезадаптивному стилю реагирования субъекта, приводящему к ущербу для его физического или эмоционально-психического здоровья. Виктимизацию принято рассматривать как процесс или/и конечный результат преобразование личности в жертву, процесс реализации вовне присущей личности виктимности. Е. В. Руденский [16], рассматривает виктимизацию - как социально-психологический механизм накопления (усиления) виктимности личности в онтогенезе, в результате дефекта онтогенетической социализации.

Существует несколько классификаций виктимности. Так, специалисты в области права выделяют четыре вида данной «способности»: индивидуальную, видовую, групповую, массовую [1]. А.М. Столяренко [18], рассматривая явление виктимности утверждает, что в психологии данное понятие представлено значительно подробнее и, в зависимости от критериев исследования, дополнительно разделяется:

- по доминирующим психологическим механизмам - на эмоционально-волевую, познавательную, мотивационную, смешанную;

- по проявлениям в различных жизненных ситуациях - на политическую, экономическую, криминальную, бытовую, транспортную и др.;

- по уровню выраженности - на слабовыраженную, средневыраженную и сильновыраженную;

- по отношению к профессиональной деятельности - на непрофессиональную (общегражданскую) и профессиональную;

- по времени протекания - на ситуативную, стабильную и относительно стабильную.

А.М. Столяренко указывает, что типология виктимности используется в процессе проведения психовиктимологических исследований, составления обобщенных психовиктимологических портретов личности и групп, при анализе поведения в различных критически сложных жизненных ситуациях и разработке психологических рекомендаций по обеспечению безопасности [18].

Изучая особенности виктимного поведения и факторы его детерминации, специалисты обращают внимание на особенности формирования моделей поведения на разных этапах онтогенетического развития. Причем, наиболее важное значение при анализе онтогенеза развития ребенка придается характеру воспитания, наличию и специфики психической травматизации ребенка, сложной структуре его взаимоотношений с родителями, воспитателями и сверстниками, переживанию ребенком депривирующих факторов различной природы [6; 28-30].

Таким образом, процесс онтогенетической виктимизации может быть рассмотрен только в контексте современного социокультурного влияния.

Рассматривая социокультурные детерминанты виктимности и процесс виктимизации необходимо и возможно рассматривать его как онтогенетический процесс деформационного личностного развития, возникающего в результате комплексного влияния факторов специфического и неспецифического характера. Отметим, что рассматривая депривационный механизм виктимизации необходимо выделять специфику действу- 
ющих дефицитов, определяющих индивидуальную матрицы онтогенетической виктимизации.

Исследуя факторное и структурное наполнение матрицы виктимизации обозначим роль семейного воспитания в виктимогенезе личности. Опираясь на положения отечественных авторов (Б.Г. Ананьев, Л.С. Выготский) отмечающих в своих работах что « ... именно среда (предметная и социальная) является источником психического развития, осуществляющегося в процессе интериоризации» [2], будем рассматривать развитие психических процессов ребенка в контексте его средового окружения, выступающего основой для формирования «социальной структуры личности...» [8, с. 145-146]. Данный подход определяет наиважнейшую роль социальной среды, в которой растет и развивается ребенок, в формировании особенностей его психики и мироощущения.

Говоря о базовом мироощущении, основанном на опыте взаимодействия ребенка с социальной средой, Э. Берн вводит понятие экзистенциального благополучия - неблагополучия и определяет базовые экзистенциальные позиции, обусловливающие специфику дальнейшего развития его личности [7]. Анализируя данный подход, Я. Стюарт и В.Джойс отмечают, разницу мировоззрения ребенка в ситуации дифференциации базовых позиций, формирование которых происходит только в ситуации совместной деятельности с окружающими его взрослыми. Развитие личности, по мнению автора, определяется ожиданиями ближайшей социализирующей группы, предложенными ценностями и идеалами, поставленными перед ним задачами на разных возрастных этапах [19].

Значимость роли ближайшей социализирующей среды отмечают и такие авторы как: А.Н. Леонтьев, рассматривающий процесс социализации через деятельностный подход [12, с. 228]; Г.М. Андреева, обозначающая социализацию как двусторонний процесс, включающий в себя усвоение человеком социального опыта при его активном воспроизводстве индивидом через систему социальных связей [3]; Е.А. Лобанова, рассматривающая процесс социализации через совместную деятельность людей и их общение [13].

Близкий подход наблюдается и в зарубежной психологии, рассматривающей вопросы материнского отдаления и нарушение взаимодействия мать-ребенок как основополагающие для травмирования ребенка (P. Bensussan [28]; W. Bernet, M.Z. Wamboldt, W.E. Narrow [29]; W. von Boch-Galhau [30]).

Таким образом, именно семья как первичная социальная группа, агент социализации, определяет качество социализации и факторы, способствующие нарастанию виктимных дефицитов или их компенсации. М.А. Демьяненко отмечает, что условия семейного воспитания могут выступать в качестве значимого фактора жизненного неблагополучия ребенка. Семейное неблагополучие вызывает огромное количество проблем в образе жизни, развитии и поведении детей, зачастую приводит к искажению их ценностных и нравственных ориентаций, приводит к серьезной психологической травматизации, вызывает дисбаланс в сфере межличностного взаимодействия, способствует педагогической запущенности. Если семья находится в зоне социальноэкономического и/или психолого-педагогического риска, то зачастую формы и способы воспитания приобретают деструктивный характер что приводит к формированию у ребенка искаженного внутреннего мира, закрепляет деструктивные формы поведения [9]. Похожие данные приводятся и в исследованиях L.B. Murphy отмечающего, что специфика развития ребенка зависит от степени близости с первичным объектом (матерью), частоты взаимодействия с ним и интенсивности стимула, вызывающего эмоции [27]. 
Как показывают исследования О.О. Андронниковой [4], И.А. и Н.В. Фурмановых [22], дети, не имеющие опыта теплых семейных отношений, любви, заботы, участия отличаются от домашних детей базовым недоверием, эмоциональной и поведенческой неадекватностью.

С. К. Нартова-Бочавер указывает, что семейное неблагополучие ведет к формированию депривированного психологического пространства личности. Автор подчеркивает, что депривированность как личностное качество, в свою очередь, представляет собой результат и условие пониженной личностной эффективности и сочетается с разными формами дезадаптации, приводя к ослаблению личной ответственности, неспособности принимать решения, и способствует развитию виктимности [14].

Рассматривая детерминанты и индукторы онтогенетичекой виктимизации личности отметим явление социально-психологической депривации личности. Термин депривации означает отсутствие удовлетворения или недостаточное удовлетворение жизненно важных потребностей личности. Социально-психологическая депривация - лишение человека выстраивания адаптивных межличностных отношений, приводящих к невозможности удовлетворения потребностей во взаимодействии. В своих работах Е.В Руденский рассматривает следующие факторы, которые влекут за собой виктимизации личности: дефицит аттракции, дефицит взаимопонимания и дефицит ролевой компетенции родителя или лица его заменяющего, принимая их как компоненты социально-психологической депривации [16]. Указанные дефициты возникают в семейных отношениях в ситуации полноценной семьи, при нарушении эмоциональной связи, несформированности дружеских чувств, симпатий, любви.

Особенно остро дефициты эмоционального принятия и близости наблюдаются в условия детского дома. Дефицит аттракции и взаимопонимания между родителем или лицом заменяющим его и ребенком могут стать причиной возникновением тревоги, которая приводит к деструктивному функционированию, виктимной социализации.

\section{Методология исследования}

Для исследования социально-психологической депривации как детерминации онтогенетической виктимизации личности было проведено эмпирическое исследование на базе муниципального бюджетного образовательного учреждения г. Новосибирска совместно с психологом Е.В. Агрызковой. В исследовании приняли участие две группы испытуемых, дети из детского дома - 20 человек и 20 человек проживающих в семьях. Возрастной диапазон испытуемых 14-16 лет. Для исследования были использованы методики: Опросник Р. Кеттелла, Опросник социально-психологической адаптации К. Роджерса и Р. Даймонда, Методика С.К. Нартова-Бочавер «Психологическое пространство личности». В качестве метода математической обработки использовался U-критерий Манна-Уитни предназначенный для оценки различий между двумя выборками по уровню какого-либо признака, количественно измеренного и корреляционный анализ.

Результаты и их обсуждение

Результаты математической обработки U-критерий Манна-Уитни между двумя выборками по методике Р. Кеттела позволяют сделать вывод о достоверной разнице 
между исследуемыми выборками (p<0,05), по показателям A, H, C, F, G, L, O, Q3, Q4. Кроме того значима разница виктимологического статуса испытуемых. Так в группе 1 (детский дом) 7 испытуемых показали статус «Виктим», что означает множество дефицитов и наличие виктимной трансформации личности. 13 человек обладают статусом «Личная виктимность», что говорит о наличии некоторых дефицитов, характеризующих низкие коммуникативные умения, снижение адаптационных способностей, ригидность реагирования. Статус «Субъект» не присвоен не одному испытуемому. Это означает, что в группе испытуемых из детского дома нет испытуемых, способных справляться с различными проблемными ситуациями, не прибегая к неадаптивным способам и демонстрирующих высокую степень социализированности.

Результаты испытуемых 2 группы (дети из семей) иные: 1 испытуемый демонстрирует статус «Виктим», «Личная виктимность» свойственна 17 испытуемым, 2 имеют статус «Субъект». Это означает что дети из семей, не зависимо от ее микроклимата, обладают значительно большей компетентностью, способностью адекватно реагировать на возникающие сложности. Ряд значимых отличий получены по группам при сравнении показателей теста социально-психологической адаптации К. Роджерса и Р. Даймонда (см. табл. 1) и методике С. К. Нартова-Бочавер «Психологическое пространство личности» (см. табл. 2).

Таблица 1

Сравнительные результаты между двумя выборками по опроснику социальнопсихологической адаптации К. Роджерса и Р. Даймонда (U-критерий Манна-Уитни)

\begin{tabular}{|r|r|r|r|r|r|r|}
\hline Адаптация & \multicolumn{1}{|c|}{$\begin{array}{c}\text { Самоприня- } \\
\text { тие }\end{array}$} & $\begin{array}{c}\text { Принятие } \\
\text { других }\end{array}$ & $\begin{array}{c}\text { Эмоциональ- } \\
\text { ная комфорт- } \\
\text { ность }\end{array}$ & $\begin{array}{c}\text { Интеграль- } \\
\text { ность }\end{array}$ & $\begin{array}{c}\text { Стремлениек } \\
\text { доминирова- } \\
\text { нию }\end{array}$ & Эскапизм \\
\hline 143,000 & 42,500 & 136,000 & 7,000 & 5,500 & 15,000 & 51,500 \\
\hline 353,000 & 252,500 & 346,000 & 217,000 & 215,500 & 225,000 & 261,500 \\
\hline$-1,543$ & $-4,262$ & $-1,733$ & $-5,222$ & $-5,264$ & $-5,008$ & $-4,025$ \\
\hline $127 a$ &, 000 &, 086 &, 000 &, 000 &, 000 &, 000 \\
\hline
\end{tabular}

Результаты позволяют сделать вывод о достоверно более низкой адаптации детей из первой группы. Достоверные различия по шкалам Самопринятие, Эмоциональная комфортность, Стремление к доминированию, Эскапизм. Что позволяет сделать вывод о достоверно более низком самоконтроле детей из детского дома, высокой тревоге, беспокойстве, страхе, аффективности проявлении чувств, эмоциональной некомпетентности.

Таблица 2

Сравнительные результаты между двумя выборками по методике С.К. НартоваБочавер (U-критерий Манна-Уитни)

\begin{tabular}{|r|r|r|r|r|r|r|}
\hline $\begin{array}{c}\text { СФТ (суверен- } \\
\text { ность физ. } \\
\text { тела) }\end{array}$ & $\begin{array}{c}\text { СТ (суверен- } \\
\text { ность терри- } \\
\text { тории) }\end{array}$ & $\begin{array}{c}\text { СВ (суверен- } \\
\text { ность мира } \\
\text { вещей) }\end{array}$ & $\begin{array}{c}\text { СП (суверен- } \\
\text { ность привы- } \\
\text { чек) }\end{array}$ & $\begin{array}{c}\text { СС (суверен- } \\
\text { ность со- } \\
\text { циальных } \\
\text { связей) }\end{array}$ & $\begin{array}{c}\text { Сц (суверен- } \\
\text { ность ценно- } \\
\text { стей) }\end{array}$ & СпП \\
\hline 20,500 & 49,500 & 26,500 & 72,000 & 74,000 & 69,500 & 269,500 \\
\hline 230,500 & 259,500 & 236,500 & 282,000 & 284,000 & 279,500 & $-3,811$ \\
\hline$-4,876$ & $-4,120$ & $-4,718$ & $-3,497$ & $-3,490$ & $-3,561$ &, 000 \\
\hline, 000 &, 000 &, 000 &, 000 &, 000 &, 000 \\
\hline
\end{tabular}


Анализ достоверных различий позволяет сделать вывод о достоверной разнице между подгруппами испытуемых. В первой группе (детский дом) характерны такие показатели как депривированность в переживание дискомфорта, вызванного прикосновениями, запахами, принуждением в отправлении его физиологических потребностей; депривированность в отсутствии территориальных границ; непризнание права на личные вещи; насильственное принятие неблизких ценностей; низкий общий уровень суверенности психологического пространства личности.

Анализ взаимосвязи между виктимными синдромами и параметрами нарушениями суверенного пространства (см. табл. 3) и социально-психологической адаптации (см. табл. 4), проведенный при помощи корреляционного анализа также позволяет сделать ряд выводом.

Таблица 3

Результаты взаимосвязи виктимных синдромов с показателями психологического пространства личности по методике С.К. Нартова-Бочавер

\begin{tabular}{|c|c|c|c|c|c|c|c|}
\hline & $\begin{array}{l}\text { СФТ (суве- } \\
\text { ренность } \\
\text { физ.тела) }\end{array}$ & $\begin{array}{l}\text { СТ (суве- } \\
\text { ренность } \\
\text { террито- } \\
\text { рии) }\end{array}$ & $\begin{array}{l}\text { СВ (суве- } \\
\text { ренность } \\
\text { мира ве- } \\
\text { щей) }\end{array}$ & $\begin{array}{c}\text { сп (суве- } \\
\text { ренность } \\
\text { привычек) }\end{array}$ & $\begin{array}{c}\text { СС (суве- } \\
\text { ренность } \\
\text { социальных } \\
\text { связей) }\end{array}$ & $\begin{array}{c}\text { СЦ (суве- } \\
\text { ренность } \\
\text { ценностей) }\end{array}$ & СПП \\
\hline \multirow{2}{*}{$\begin{array}{l}\text { Тревожный } \\
\text { синдром }\end{array}$} &,$- 466 * *$ &,$- 459 * *$ &,$- 610 * *$ &,$- 378 *$ &,- 256 &,$- 445 * *$ &,$- 443 * *$ \\
\hline & ,002 & ,003 & ,000 & ,016 & 111 & ,004 & ,004 \\
\hline \multirow{2}{*}{$\begin{array}{l}\text { Неадап- } \\
\text { тивный } \\
\text { синдром }\end{array}$} &,$- 413 * *$ &,- 306 &,$- 326 *$ &,$- 343 *$ &,$- 562 * *$ &,$- 315^{*}$ &,$- 467 * *$ \\
\hline & ,008 & ,055 & ,040 & ,030 & ,000 & ,047 & ,002 \\
\hline \multirow{2}{*}{$\begin{array}{l}\text { Акцио- } \\
\text { нальный } \\
\text { синдром }\end{array}$} &,$- 372 *$ &,- 312 &,$- 436 * *$ &,- 086 &,- 309 &,- 191 &,$- 324^{*}$ \\
\hline & ,018 & ,050 & ,005 & ,598 & ,053 & ,237 & ,041 \\
\hline \multirow{2}{*}{$\begin{array}{l}\text { Аксеоло- } \\
\text { гический } \\
\text { синдром }\end{array}$} & ,077 & 142 & ,099 &,- 138 & ,042 & 181 &,- 021 \\
\hline & & ,381 &, 544 & ,395 & ,796 & ,263 & ,899 \\
\hline
\end{tabular}

Таблица 4

Результаты взаимосвязи виктимных синдромов с показателями социальнопсихологической адаптации К. Роджерса и Р. Даймонда

\begin{tabular}{|c|c|c|c|c|c|c|c|}
\hline & Адаптация & $\begin{array}{l}\text { Самопри- } \\
\text { нятие }\end{array}$ & $\begin{array}{c}\text { Принятие } \\
\text { других }\end{array}$ & $\begin{array}{c}\text { Эмоцио- } \\
\text { нальная } \\
\text { комфорт- } \\
\text { ность }\end{array}$ & $\begin{array}{c}\text { Интеграль- } \\
\text { ность }\end{array}$ & $\begin{array}{c}\text { Стремление } \\
\text { к домини- } \\
\text { рованию }\end{array}$ & Эскапизм \\
\hline \multirow{2}{*}{$\begin{array}{l}\text { Тревожный } \\
\text { синдром }\end{array}$} & ,032 &,$- 442 * *$ &,$- 419 * *$ &,$- 666 * *$ &,$- 579 * *$ &,$- 614^{* *}$ & , $406 * *$ \\
\hline & ,846 & ,004 & ,007 & , 000 &, 000 & , 000 & ,009 \\
\hline \multirow{2}{*}{$\begin{array}{l}\text { Неадап- } \\
\text { тивный } \\
\text { синдром }\end{array}$} &,- 043 &,- 263 &,- 041 &,$- 383 *$ &,$- 571 * *$ &,$- 315^{*}$ & 278 \\
\hline & ,794 & 101 & ,804 & ,015 &, 000 & ,048 & ,082 \\
\hline \multirow{2}{*}{$\begin{array}{l}\text { Акцио- } \\
\text { нальный } \\
\text { синдром }\end{array}$} &,- 093 &,$- 499 * *$ &,- 040 &,$- 388 *$ &,$- 461 * *$ &,$- 423 * *$ & ,257 \\
\hline & 570 & 001 & ,806 & ,013 & ,003 & 007 & 110, \\
\hline \multirow{2}{*}{$\begin{array}{l}\text { Аксеоло- } \\
\text { гический } \\
\text { синдром }\end{array}$} &,- 266 & ,211 & ,139 & 112 & 130 & ,293 &,- 137 \\
\hline & ,097 & 192 & ,394 & ,493 & ,424 & ,067 & ,400 \\
\hline
\end{tabular}


По результатам корреляционного анализа можно сделать вывод, что тревожной синдром отрицательно связан с такими параметрами как суверенность физического тела, суверенной территории, суверенность мира вещей, суверенность привычек, суверенность социальных связей, суверенность ценностей. Таким образом при наличии тревожного синдрома можно говорить о достоверном нарушении психологического пространства личности, депривированности. Необходимо отметить, что тревожный синдром также достоверно характеризуется такими показателями как: нарушение самопринятия, принятия других, низким уровнем эмоционального комфорта, неспособностью к интегральности, отсутствием стремления доминированию при высокой склонности к эскапизму. Это означает, что тревожный синдром характеризуется высокой степенью депривированности и нарушением социальной адаптации. Возможно, именно тревожный синдром является основой для виктимной дезадаптации личности. Неадаптивный синдром имеет значимые коллекционные связи с параметрами: нарушение суверенности физического тела, суверенности мира вещей, привычек, суверенность социальных связей, суверенность ценностей. Из параметров адаптации данный синдром имеет достоверные связи с низким уровнем эмоциональной комфортности, нарушением интегральности, низким уровнем стремления к доминированию. Таким образом неадаптивный синдром отличается рядом параметров, говорящих о дезадаптации, тем не менее, его проявления несколько ниже чем при наличии тревожного синдрома, хотя и характеризуются достаточно высоким уровнем дефицитов суверенного пространства личности. Акциональный синдром характеризуется достоверным нарушением суверенности со физического тела и суверенности мира вещей. Отметим что акциональный синдром также связан с низким уровнем самопринятия, эмоциональным дискомфортом, нарушением интегральности и низким стремлением к доминированию. Аксиологический синдром не показал взаимосвязи с параметрами социально-психологической адаптации и нарушением суверенности психологического пространства.

Выводы

Таким образом, осуществленное исследование социально-психологической депривации как детерминанты онтогенетической виктимизации личности ребенка дает нам основания для формулирования следующих выводов:

- Личностное развитие ребенка осуществляется в тесном взаимодействии целого ряда факторов, среди которых: возрастная специфика развития, индивидуальные особенности ребенка, комплексное влияние социальной среды, во многом обусловливающей процессы воспитания и социализации.

- Наличие социально-психологической депривации в раннем возрасте может послужить развитию серьезных социально-психологических деформаций, формирующих виктимность.

- Социально-психологическая депривация выступает в качестве виктимогенного фактора и исходного дефицита онтогенетической виктимизации личности. 


\section{ЛИТЕРАТУРА}

1. Алауханов Е. Криминология. Учебник. Алматы. 2008. 429 с.

2. Ананьев Б.Г. Человек как предмет познания. СПб.: Питер, 2010. 288 с.

3. Андреева Г.М. Социальная психология. М.: Аспект Пресс, 2001. 384 с.

4. Андронникова О.О. Виктимное поведение подростков: факторы возникновения и профилактика: монография. Новосибирск: НГИ, 2005. 300 с.

5. Андронникова О.О. Психолого-педагогические условия формирования опасных и безопасных форм поведения ребенка // Социокультурные проблемы современного человека: материалы конференции 2010 Часть 2. Материалы IV Международной научно-практической конференции (19-24 апреля 2010 г.) Часть II / под ред. Н.Я. Большуновой, О.А. Шамшиковой. Новосибирск: Изд. НГПУ, 2011. ч. II. 557 с.

6. Андронникова О.О. Роль семьи в формировании неадаптивных форм виктимного поведения детей // Семья в XXI веке. Сборник материалов международного экспертного симпозиума. Новосибирск, 2013. С. $156-164$.

7. Берн Э. Игры, в которые играют люди: психология человеческих взаимоотношений; Люди, которые играют в игры: психология человеческой судьбы / пер. с англ. М.: ГРАНД, 2004. 473 с.

8. Выготский Л.С. Вопросы детской (возрастной) психологии / Собрание соч. Под ред. А. М. Матюшкина. В 6-ти т. М.: Педагогика, 1982. Т. 4. С. 277-426.

9. Демьяненко M.A. Психологическая характеристика детей, испытывающих семейное неблагополучие. URL: http://nsportal.ru/psikhologicheskaya-kharakteristika-detey-ispytyvayushchikh-semeynoe-neblagopoluchie (дата обращения: 10.01.2019)

10. Запорожец А.В. Психологическое изучение развития моторики ребенка-дошкольника Вопросы психологии ребенка дошкольного возраста / Под ред. А.Н. Леонтьева и А.В. Запорожца. М., 1995. С. 112-122.

11. Захаров А.И. Происхождение детских неврозов и психотерапия. М.: ЭКСМО-Пресс, 2000. 448 с.

12. Леонтьев А.Н. Деятельность. Сознание. Личность. М.: Смысл, 2005. 352 с.

13. Лобанова Е.А. Дошкольная педагогика: учебно-методическое пособие. Балашиха: РХТЦ, 2012. 76 с.

14. Нартова-Бочавер С.К. Человек суверенный: психологическое исследование субъекта в его бытии. СПб.: Питер, 2008. 400 с.

15. Николаева Я.Г. Воспитание ребенка в неполной семье. М., Владос, 2006. 159 с.

16. Руденский Е.В. Депривационный виктимизм как социально-психологический фактор риска экстремизм. [Электронный ресурc]. URL: http://www.studsell.com/view/38186/ (дата обращения: 05.09.2018).

17. Соловьева О.В. Депривация семейного общения как детерминанта личностного развития детей, лишенных попечения родителей: дис. ... канд. психол. наук. Краснодар, 2004. 209 с.

18. Столяренко А.М. Экстремальная психопедагогика: Учеб. пособие для вузов. М.: ЮНИТИ-ДАНА, 2002. С. 385.

19. Стюарт Я., Джойс В. Современный трансактный анализ. СПб.: Социально-психологический центр, 1998.330 с.

20. Федорова Н.В. Депривация в семье как фактор делинквентного поведения подростков: монография. М-во образования и науки Рос. Федерации, Омский гос. пед. ун-т. Омск : Изд-во ОмГПУ, 2016. 243 с.

21. Франк Л.В. Виктимология и виктимность. Душанбе, 1972. С. 22.

22. Фурманов И.А. Фурманова Н.В. Психология депривированного ребенка: пособие для психологов и педагогов. М.: Гуманитар. изд. центр ВЛАДОС, 2004. 319 с.

23. Хоментаускас Г.Т. Семья глазами ребенка. М.: Педагогика, 1989. 160 с.

24. Целуйко В.М. Психология неблагополучной семьи. М.: Владос, 2003. 272 с.

25. Целуйко Н.А. Родители и дети: психология взаимоотношений в семье. Мозырь, 2006. 132 с.

26. Эльконин Д.Б. Избранные психологические труды. М.: Педагогика, 1989. 560 с.

27. Murphy L. B. Further Reflections on Resilience // The Invulnerable child. N.Y.: Guilford Press, 1987. P. 84-105.

28. Bensussan P. Parental alienation, child psychological abuse and DSM-5. Encephale. 2017, Dec; 43(6): 510-515. doi: 10.1016/j.encep.2017.08.003

29. Bernet, W., Wamboldt, M.Z., \& Narrow, W. E. Child affected by parental relationship distress. Journal of the American Academy of Child \& Adolescent Psychiatry, 2016, 55(7), 571-579. http://dx.doi.org/10.1016/j.jaac.2016.04.018

30. von Boch-Galhau, W. Parental Alienation (Syndrome) - A serious form of child psychological abuse // Neuropsychiatrie. Volume 32, Issue 3, 1 September 2018, Pages 133-148

\section{REFERENCES}

1. Alaukhanov E. Criminology. Textbook. Almaty, 2008. 429 p. (in Russian)

2. Ananiev B.G. Man as a subject of knowledge. Saint-Petersburg, Peter Publ., 2010. 288 p. (in Russian)

3. Andreeva G.M. Social Psychology. Moscow, Aspect Press Publ., 2001. 384 p. (in Russian)

4. Andronnikova O.O. Victim behavior of adolescents: factors of occurrence and prevention: monograph. Novosibirsk, NGI Publ., 2005. 300 p. (in Russian)

5. Andronnikova O.O. Psychological and pedagogical conditions of the formation of dangerous and safe forms of child behavior. Social and cultural problems of a modern person: materials of the 2010 conference Part 2. Materials of the IV International Scientific and Practical Conference (April 19 - 24, 2010). Part II / ed. N.Y. Bolsunova, O.A. Shamshikova. Novosibirsk, NGPU Publ., 2011. 557 p. (in Russian) 
6. Andronnikova O.O. The role of the family in the formation of non-adaptive forms of victimization behavior of children. Family in the XXI century. Collection of materials of the international expert symposium. Novosibirsk, 2013. p. 156-164. (in Russian)

7. Bern E. The games people play: the psychology of human relationships; People who play games: the psychology of human destiny. Moscow, GRAND Publ., 2004. 473 p. (in Russian)

8. Vygotsky L.S. Questions of child (age) psychology / Collected Works. Ed. A.M. Matyushkina. Moscow, Pedagogy Publ., 1982. vol. 4. pp. 277-426. (in Russian)

9. Demianenko M.A. Psychological characteristics of children experiencing family distress. Available at: http:// nsportal.ru/psikhologicheskaya-kharakteristika-detey-ispytyvayushchikh-semeynoe-neblagopoluchie (accessed 10 January 2019) (in Russian)

10. Zaporozhets A.V. Psychological study of the development of motor preschooler child Questions psychology of a child of preschool age / Ed. A.N. Leontiev and A.V. Zaporozhets. Moscow, 1995. pp. 112-122. (in Russian)

11. Zakharov A.I. The origin of childhood neuroses and psychotherapy. Moscow, EKSMO-Press, 2000. 448 p. (in Russian)

12. Leontyev A.N. Activity Consciousness. Personality. Moscow, Meaning Publ., 2005. 352 p. (in Russian)

13. Lobanova E.A. Preschool pedagogy: a teaching aid. Balashikha, RHTC Publ., 2012. 76 p. (in Russian)

14. Nartova-Bochiver S.K. Sovereign man: a psychological study of the subject in his being. Saint-Petersburg, Peter Publ., 2008. 400 p. (in Russian)

15. Nikolaev Ya.G. Raising a child in an incomplete family. Moscow, Vlados Publ., 2006. 159 p. (in Russian)

16. Rudensky E.V. Deprivation victimization as a socio-psychological risk factor for extremism. [Electronic resource]. Available at: http://www.studsell.com/view/38186/ (accessed 9 September 2018). (in Russian)

17. Solovyova O.V. Deprivation of family communication as a determinant of the personal development of children deprived of parental care: Diss. PhD Psychol. Sci., Krasnodar, 2004. 209 p. (in Russian)

18. Stolyarenko A.M. Extreme psychopedagogy: Textbook. manual for universities. Moscow, UNITY-DANA Publ., 2002. p. 385. (in Russian)

19. Stuart J., Joyce V. Modern transactional analysis. Saint-Peterburg, Socio-psychological center Publ., 1998.330 p. (in Russian)

20. Fedorov N.V. Family deprivation as a factor in adolescent delinquent behavior: monograph. Omsk, Publishing House OmGPU, 2016. 243 p. (in Russian)

21. Frank L.V. Victimology and victimization. Dushanbe, 1972. p. 22. (in Russian)

22. Furmanov I.A. Furmanova N.V. Psychology of a deprived child: a manual for psychologists and teachers. Moscow, Vlados Publ., 2004. 319 p. (in Russian)

23. Homentauskas G.T. Family eyes of a child. Moscow, Pedagogy Publ., 1989. 160 p. (in Russian)

24. Tseluyko V.M. Psychology of a dysfunctional family. Moscow, Vlados Publ., 2003. 272 p. (in Russian)

25. Tseluyko N.A. Parents and children: the psychology of family relationships. Mozyr, 2006. 132 p. (in Russian)

26. Elkonin D.B. Selected psychological works. Moscow, Pedagogy Publ., 1989. 560 p. (in Russian)

27. Murphy L. B. Further Reflections on Resilience // The Invulnerable child. N.Y.: Guilford Press, 1987. pp. 84-105.

28. Bensussan P. Parental alienation, child psychological abuse and DSM-5. Encephale. 2017, Dec; 43(6): 510-515. doi: 10.1016/j.encep.2017.08.003

29. Bernet, W., Wamboldt, M. Z., \& Narrow, W. E. Child affected by parental relationship distress. Journal of the American Academy of Child \& Adolescent Psychiatry, 2016, 55(7), pp. 571-579. http://dx.doi.org/10.1016/j.jaac.2016.04.018

30. von Boch-Galhau, W. Parental Alienation (Syndrome)-A serious form of child psychological abuse. Neuropsychiatrie. 2018. Vol. 32, Issue 3, pp. 133-148.

\author{
Информация об авторе \\ Андронникова Ольга Олеговна \\ (Новосибирск, Россия) \\ Кандидат психологических наук, \\ декан факультета психологии \\ Новосибирский государственный педагогический \\ университет \\ E-mail: andronnikova_69@mail.ru
}

\section{Information about the author Olga O. Andronnikova (Novosibirsk, Russia) $\mathrm{PhD}$ in Psychological Sciences Dean \\ of the Faculty of Psychology}

Novosibirsk State Pedagogical University

E-mail: andronnikova_69@mail.ru 